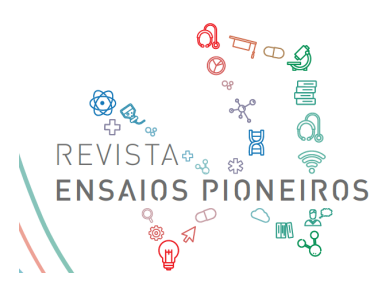

\title{
COMPARATIVO DO CONTROLE BIOLÓGICO E QUÍMICO DE Spodoptera frugiperda NA CULTURA DO MILHO
}

COMPARING BIOLOGIC WITH CHEMICAL CONTROL OF Spodoptera frugiperda IN MAIZE PRODUCTION

\author{
GARAVAZO, Fábio ${ }^{1}$; PATRONI, Bruno Henrique ${ }^{2}$; LOPES, Amarildo ${ }^{3}$; BALIEIRO, \\ Cristiano de Carvalho ${ }^{4}$ \\ ${ }^{1}$ Engenheiro Agrônomo; Centro Universitário Fundação de Ensino Octávio Bastos - Unifeob, \\ São João da Boa Vista- SP; ${ }^{2}$ Engenheiro Agrônomo; Departamento de Vendas, Corteva \\ Agriscience, São João da Boa Vista - SP; ${ }^{3}$ Engenheiro Agrônomo; Fazenda Santana, Santa \\ Cruz das Palmerias - SP; ${ }^{4}$ Engenheiro Agônomo, Docente; Centro Universitário Fundação de \\ Ensino Octávio Bastos - Unifeob, São João da Boa Vista - SP \\ fgaravazo@hotmail.com
}

RESUMO. Este trabalho objetivou avaliar a eficiência do controle biológico com baculovírus, testando dois modos de aplicação (aplicado em dose única e em três aplicações), bem como o uso do controle químico. Para isso, conduziu-se um experimento em campo com o hibrido de milho 30F35R. Foram realizados quatro tratamentos: testemunha, sem aplicação de produtos para controle; químico, com aplicação de produtos com lambda-cialotrina e flubendiamida; Biológico, com três aplicações do produto à base de Baculovirus spodoptera; e Biológico único, com aplicação única do produto à base de Baculovirus spodoptera. As plantas foram avaliadas quanto a incidência de danos causados pelas lagartas por meio da avaliação com escala Davis aos 55 DAP e em seguida foram colhidas para a avaliação da matéria seca. Verificou-se que os tratamentos biológico e biológico único apresentaram resultados estatisticamente iguais ao controle químico, e também à testemunha com relação a variável matéria seca. $\mathrm{O}$ tratamento biológico único e químico apresentaram notas reduzidas da escala Davies com relação a testemunha. O tratamento biológico apresentou valores estatisticamente iguais a testemunha e também aos outros controles. Conclui-se que o controle biológico é uma estratégia eficaz para o controle de lagartas, sendo sua aplicação única na fase inicial da cultura mais vantajosa do que a aplicação parcelada em três aplicações.

Palavras-chave: Baculovírus, Escala Davis, lagarta do cartucho, matéria-seca.

ABSTRACT. This work aimed investigate the effectiveness of biological control, evaluating two application modes (a single application of baculovirus and three applications of baculovirus), as well as chemical control. A field experiment was carried out with maize hybrid 30F35R. Four treatments were realized: a check treatment (no control used), chemical control (application of lambda-cialotrine and flubendiamide), biological control with Baculovirus spodoptera using a single application, and biological control with Baculovirus spodoptera using three applications. Maize plants were evaluated according to the Davis scale at 55 DAS (days after seedling). After, plants were harvested to dry matter evaluation. It was verified that, regarding dry matter variable, biological control with single and two application presented results statistically equal to chemical control and check treatment. Chemical control and biological control with a single application showed lower values of Davis scale than check treatment, indicating lower damage. Biological control with two applications presented values of Davies scale similar to check treatment and also the other controls. It was concluded that biological control is an efficient management strategy to control fall armyworm, and the single 
application at the initial phase of the maize culture is more effective than the use of three applications.

Keywords: Baculovirus, Davis scale, fall armyworm, dry-matter.

\section{INTRODUÇÃO}

O milho é um dos cereais mais importantes no cenário de produção e consumo mundial. Nas últimas décadas, a produção de milho cresceu significativamente, sendo que na safra 2018/2019, o milho foi o cereal produzido em maior quantidade no mundo, e foi a única cultura a ultrapassar a marca de 1 bilhão de toneladas, destacando-se diante de antigos concorrentes, como o arroz e o trigo (FAO, 2020). De acordo com Miranda (2018), o milho destaca-se também por seus diversos usos, como fonte de alimento para suínos, aves e bovinos, produção de polímeros e conbustíveis, utilização do grão para obtenção de amido, farinha e óleos vegetais.

O milho é um produto de elevada importância para a agricultura brasileira, cultivado em todas as regiões do País, em mais de dois milhões de estabelecimentos agropecuários. Na safra de 2019/2020 a produção de milho no Brasil é estimada em aproximadamente 98 milhões de toneladas (CONAB, 2020), sendo que o Brasil configura-se como segundo maior exportador de milho no mundo (USDA, 2020). Segundo Contini et al. (2019) nas últimas décadas, a cultura passou por diversas transformações, destacando-se a redução de seu cultivo como cultura de subsistência em pequenos estabelecimentos, e o aumento do seu papel como cultura comercial de elevada eficiência, com deslocamento geográfico e temporal da produção. Atualmente o milho esta inserido em sistemas de produção agríola, e a segunda safra é responsável pela maior parte do milho produzido no Brasil (CONAB, 2020). Tais mudanças levaram ao aumento signficativo da produtividade no Brasil, mas também a necessidade de manejo eficiente para os problemas fitossanitários advindos da intensificação da produção (FANCELLI, 2015).

A ocorrência de doenças, plantas daninhas e insetos pragas, juntos ou individualmente, podem reduzir o potencial produtivo da lavoura de milho. As pragas em especial, podem afetar de maneira total ou parcial esse potencial produtivo, causando impactos econômicos significativos na cadeia produtiva do milho (OLIVEIRA et al., 2014). Dentre o complexo de insetos que atacam a cultura, a lagarta do cartucho (Spodoptera frugiperda) é considerada a principal praga do milho no Brasil, demanda alto investimento para o seu controle, e pode causar perdas de até $60 \%$ na produção (CRUZ et al., 2020). As larvas mais novas consomem tecidos de folha de um lado, deixando a epiderme oposta intacta. Depois do segundo ou terceiro instar, as larvas começam a fazer buracos nas folhas, se alimentado em seguida do cartucho das plantas de milho, produzindo uma característica fileira de perfurações nas folhas (CRUZ et al., 2020).

O manejo integrado de pragas (MIP) é considerado umas das melhores ferramentas de controle de pragas, no qual utilizam-se todas as técnicas de controle apropriadas (como as de natureza química, biológica e genética), a fim de manter a população da praga em níveis abaixo daqueles capazes de causar danos econômicos (WAGUIL et al., 2020).

O controle químico é uma das técnicas disponíveis para controle de pragas, amplamente utilizado pelos produtores. $\mathrm{O}$ tratamento de sementes e pulverizações foliares com inseticidas são práticas utilizadas para o controle químico da lagarta do cartucho. Diferentes grupos químicos de inseticidas tem sido testados e utilizados para reduzir a população da lagarta do cartucho nas lavouras. Segundo Toscano (2012), o inseticida regulador do crescimento de insetos lufenurom (bezodiuréias) foi o mais eficiente no controle da lagarta do cartucho e ainda 
apresentou menos impacto negativo sobre a população dos agentes biológicos quando comparado com o organofosforado clorpirifós. Oliveria e Nunes (2017) verificaram que tanto inseticidas do grupo dos piretróides (lambda-cialotrina), flubendiazinas (diamidas) e organofosforados (profenofós) foram eficientes no controle da lagarta do cartucho.

O controle biológico, outra técnica utilizada no MIP, tem assumido cada vez mais importância no manejo integrado de pragas, dada a importância da produção sustentável no cenário econômico e ambiental. Este método consiste no uso de predadores e inimigos naturais para o controle da praga alvo, e é usado em em combinação com outros métodos como o químico, para a manutenção das pragas abaixo do nível de dano econômico (WAGUIL et al, 2020).

Dentre os inimigos naturais da lagarta do cartucho destacam-se vírus, bactérias, fungos, parasitoides e nematóides. Os vírus do gênero Baculovirus são os de maior ocorrência e um dos mais estudados dentre os vírus patogêncios de insetos. O Baculovirus usado atualmente no controle da lagarta do cartucho do milho é um vírus da poliedrose nuclear (VPN). Foi descrito na literatura como Baculovirus spodoptera e vem se tornando alternativa viável no controle de S. frugiperda (VALICENTE; TUELHER, 2010; BEHLE; POPHAN, 2012) Os sintomas típicos da infecção das lagartas por Baculovirus são perda de apetite, geotropismo negativo, clareamento da epiderme devido ao acúmulo de vírus nos núcleos das células da epiderme e tecido adiposo (VALICENTE;TUELHER, 2010).

Devido ao uso indiscriminado de alguns produtos químicos, é comum verificar a redução de sua eficiência e algumas regiões, sendo necessário testar diferentes ingredientes ativos, bem como associações de técnicas, sobretudo as biológicas, como o Baculovírus, para aumentar a eficiência do controle da lagarta do cartucho. O uso destas diferentes técnicas apresenta eficiência variável dependendo da variedade e/ou híbrido utilizado, bem como de acordo com a região de cultivo (FANCELI, 2015).

Neste contexto, o presente estudo teve como objetivo avaliar o uso do controle biológico com Baculovírus, considerando dois modos de aplicação (única e três aplicações) comparado ao tratamento químico convencional (aplicação de inseticida lambda-cialotrina e flubendiamida) e testemunha, com relação a eficiência de controle de lagartas-do-cartucho (Spodoptera frugiperda) na cultura do milho, na região de São João da Boa Vista-SP.

\section{METODOLOGIA}

A área experimental localiza-se no interior do estado de São Paulo, a uma latitude $21^{\circ} 46^{\prime} 26^{\prime \prime}$ sul e a uma longitude $47^{\circ} 05^{\prime} 11^{\prime \prime}$ oeste e com altitude de 650 metros, no município de Santa Cruz das Palmeiras, SP.

Para a realização do trabalho foi utilizado o híbrido de milho $30 \mathrm{~F} 35 \mathrm{R}$ que não possui biotecnologia de resistência ao complexo de lagartas. O plantio foi realizado dia 10 de dezembro de 2019 com uma plantadeira da marca Jumil modelo J2S de 3 linhas com espaçamento de 0,75 metros entre linhas com regulagem para 60.000 plantas por hectare. As adubações foram de $300 \mathrm{~kg} / \mathrm{ha}$ da fórmula $08-28-16$ no plantio e $400 \mathrm{~kg} / \mathrm{ha}$ de $20-00-20 \mathrm{em}$ cobertura.

Foram realizados quatro tratamentos com quatro repetições, sendo o delineamento experimental de blocos casualizados. Os tratamentos foram: Testemunha (T), sem aplicação de produtos para controle de lagartas, Químico (Q), Biológico (b) e Biológico único (B) que consistiu na aplicação do produto em dose dobrada apenas na primeira aplicação. Para os tratamentos biológicos foi utilizado o inseticida biológico a base de Baculovirus spodoptera e para o tratamento químico foram utilizados produtos a base dos seguintes ingredientes ativos: 
lambda-cialotrina e flubendiamida. As variáveis matéria seca (MS) e avaliação de dano segundo a escala Davies (AED), .foram avaliadas nos tratamentos ao final do experimento. A escala

Davis consiste em uma avaliação visual das folhas de milho, para determinação de uma nota (a qual varia de 0 a 9) de acordo com o nível de dano causado pela lagarta nas folhas de milho (0: nenhum dano, e 9: cartucho muito danificado) (DAVIES et al., 1992).

Para a tomada de decisão das pulverizações foi utilizada uma armadilha tipo delta com feromônio sexual (Figura 1) e a escala Davis et al (1992). As aplicações foram realizadas com equipamento costal com ponteira de pulverização tipo jato plano com ângulo de 110 graus e vazão de 150 litros/ha.

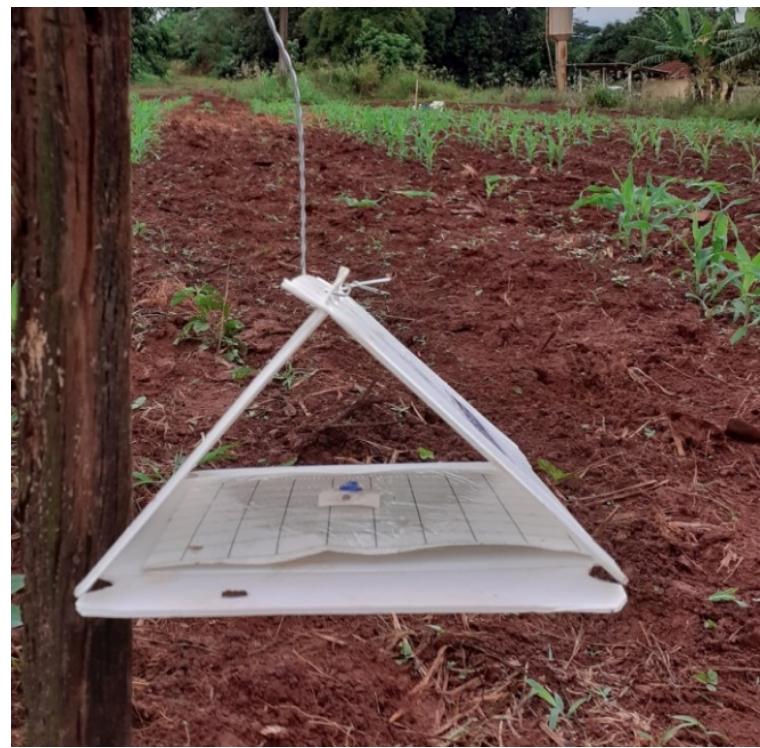

Figura 1- Armadilha tipo delta com feromônio sexual utilizada na tomada de decisão para realização das aplicações (Fonte: Próprio autor).

A primeira aplicação dos tratamentos (Figura 2) foi realizada no dia 13 DAP (dias após o plantio) sendo utilizado no tratamento biológico (b) a dose de 50 gramas do produto comercial (p.c) por hectare; no tratamento biológico único (B) a dose de 100 gramas p.c por hectare; e no tratamento químico $(\mathrm{Q})$ a lambda-cialotrina na dose de $30 \mathrm{~mL}$ de p.c por hectare.

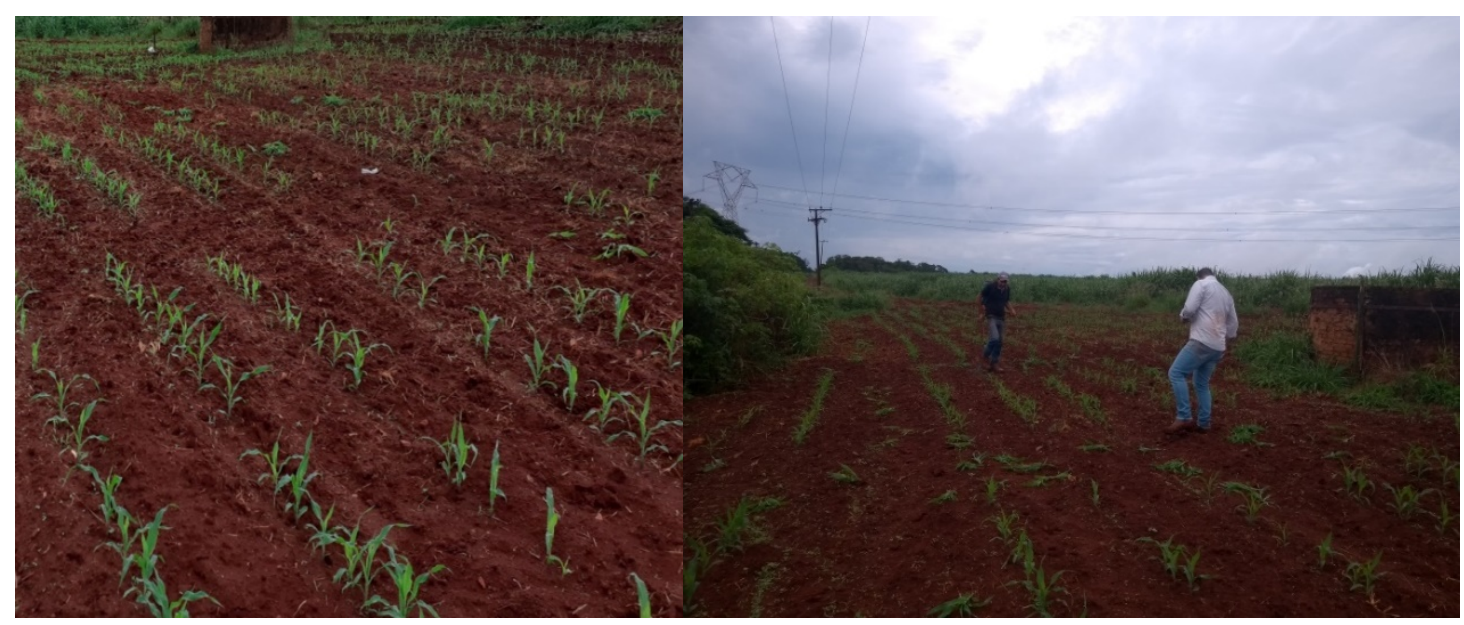

Figura 2- Primeira aplicação dos tratamentos, aos 13 DAP (Fonte: Próprio autor). 
A segunda aplicação no tratamento biológico (b) ocorreu aos 23 DAP, com 50 gramas do p.c. por hectare e, no tratamento químico (Q), a flubendiamida na dose de $150 \mathrm{~mL}$ p.c. por hectare. Por fim a terceira e última aplicação ocorreu aos 30 DAP (Figura 3), sendo aplicado no tratamento biológico (b) 50 gramas do p.c. por hectare e no tratamento químico (Q) a flubendiamida na dose de $150 \mathrm{~mL}$ p.c. por hectare.

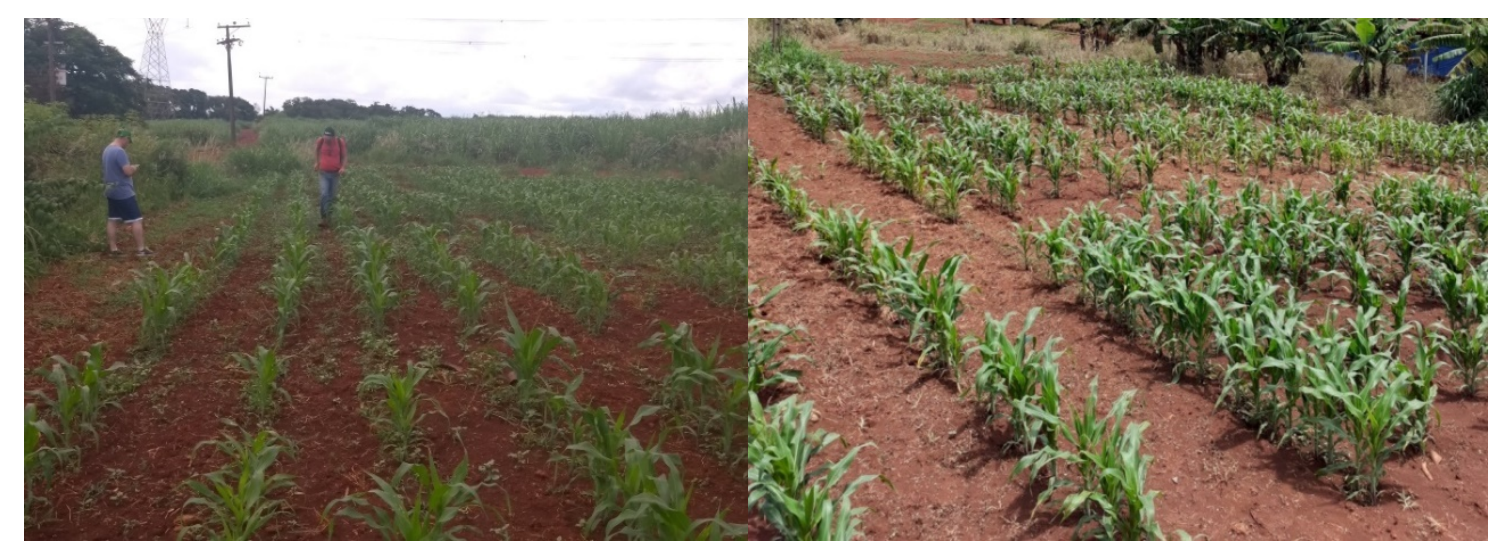

Figura 3- Realização da terceira aplicação dos tratamentos biológico (b) e químico (Q), aos 30 DAP (Fonte: Próprio autor).

Para controle de plantas invasoras aplicou-se o glifosato, na dose de $3 \mathrm{~L} / \mathrm{ha}$ de p.c. e atrazina na dose de $2,5 \mathrm{~L} /$ ha p.c. aos 25 DAP. O volume de calda utilizado foi de $200 \mathrm{~L} / \mathrm{ha}$. As plantas de milho foram coletadas aos 55 DAP, sendo então submetidas a secagem em estufa a $60^{\circ} \mathrm{C}$ por 72 horas para análise de matéria seca.

Foram realizadas análises descritivas das variáveis avaliadas visando estabelecer o padrão característico e verificar das pressuposições comumente utilizadas em análises de dados experimentais (Figura 4). Para avaliação das variáveis "Matéria Seca" (MS) e "Avaliação Escala Davis" (AED), segundo os diferentes tratamentos, os dados foram submetidos à Análise de Variância e em caso de teste $\mathrm{F}$ significativo, foi utilizado o teste de Tukey como procedimento nas respectivas comparações. Todas as análises estatísticas foram realizadas com auxílio do Programa Agroestat (BARBOSA; MALDONADO, 2010).

\section{RESULTADOS E DISCUSSÃO}

Os números de observações e as estimativas de médias, desvios padrão, coeficientes de variação, valores de mínimo e máximo das variáveis "Matéria Seca" (MS) e "Avaliação Escala Davis" (AED), de acordo com os diferentes tratamentos encontram-se na Tabela 1.

Tabela 1- Números de observações (N), médias (MED), desvios padrão (DP), coeficientes de variação $(\mathrm{CV})$, valores de mínimo (MIN) e máximo (MAX) para as variáveis "Matéria Seca" (MS) e "Avaliação Escala Davis" (AED), segundo os diferentes tratamentos. 


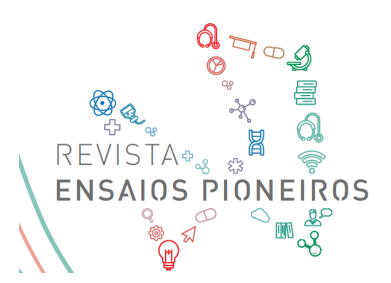

http://ensaiospioneiros.usf.edu.br

\begin{tabular}{ccccc}
\hline & \multicolumn{5}{c}{ MS } & \\
\hline & $\mathrm{T} 1$ & $\mathrm{~T} 2$ & $\mathrm{~T} 3$ & $\mathrm{~T} 4$ \\
\hline $\mathrm{N}$ & 4,00 & 4,00 & 4,00 & 4,00 \\
MIN & 67,00 & 106,50 & 88,00 & 112,00 \\
MAX & 114,00 & 118,5 & 126,50 & 127,50 \\
MED & 88,88 & 112,00 & 98,38 & 123,13 \\
DP & 22,31 & 6,40 & 18,77 & 7,44 \\
CV & 25,10 & 5,71 & 19,08 & 6,04 \\
\hline & & AED & & \\
\hline N & T1 & T2 & T3 & T4 \\
MIN & 4,00 & 4,00 & 4,00 & 4,00 \\
MAX & 6,00 & 3,00 & 3,00 & 3,00 \\
MED & 8,00 & 5,00 & 7,00 & 4,00 \\
DP & 7,25 & 4,25 & 5,50 & 3,25 \\
CV & 0,96 & 0,96 & 1,73 & 0,50 \\
\hline
\end{tabular}

$\mathrm{T} 1$ = Testemunha; $\mathrm{T} 2$ = Biológico1x; T3 = Biológico2x; T4 = Químico

Fonte: Próprio autor

As estimativas de médias variáveis "Matéria Seca" (MS) e "Avaliação Escala Davis" (AED), segundo os diferentes tratamentos, encontram-se na Tabela 2.

Verifica-se na Tabela 2, que para a variável MS, os tratamentos T2, T3 e T4 diferiram significativamente $(\mathrm{P}<0,05)$ em comparação ao tratamento $\mathrm{T} 1$, porém não foi evidenciada diferença significativa $(\mathrm{P}>0,05)$ entre tratamento $\mathrm{T} 1$ e os tratamentos $\mathrm{T} 2$ e $\mathrm{T} 3$.

Para a variável EAD, não foram encontradas diferenças significativas $(\mathrm{P}>0,05)$ entre os tratamentos T1 e T3, nem tão pouco entre os tratamentos T2, T3 e T4. Entretanto, o tratamento

$\mathrm{T} 1$ diferiu significativamente $(\mathrm{P}<0,05)$ dos tratamentos $\mathrm{T} 2$ e $\mathrm{T} 4$.

Tabela 2- Estimativas de médias das variáveis "Matéria Seca" (MS) e "Avaliação Escala Davis" (AED), segundo os diferentes tratamentos.

\begin{tabular}{ccccc}
\hline T1 & T2 & T3 & T4 \\
\hline \multicolumn{5}{c}{ MS } \\
\hline $88,88^{\mathrm{B}}$ & $112,00^{\mathrm{A}, \mathrm{B}}$ & & $98,38^{\mathrm{A}, \mathrm{B}}$ & $123,13^{\mathrm{A}}$ \\
\hline \multicolumn{5}{c}{ AED } \\
\hline $7,25^{\mathrm{A}}$ & $4,25^{\mathrm{B}}$ & & $5,50^{\mathrm{A}, \mathrm{B}}$ & $3,25^{\mathrm{B}}$
\end{tabular}

T1 = Testemunha; T2 = Biológico1x; T3 = Biológico2x; T4 = Químico. Médias seguidas por uma mesma letra maiúscula na linha, não diferem entre si pelo Teste de Tukey $(\mathrm{p}>0,05)$.

Fonte: Próprio autor

Portanto, a efciência da aplicação do controle químico e biológico foi semelhante, embora o controle químico (T4) tenha apresentado resultados superiores a testemunha para ambas as variáveis observadas, e o controle biológico (T2 e T3) apresentou valores estatisticamente iguais à testemunha para matéria seca (T2 e T3) e escala Davies (somente T3).

Oliveira e Nunes et al. (2017) também relataram elevada eficiência dos inseticidas lambdacialotrina e flubendazina na mortalidade de lagartas e controle dos sintomas nas plantas 
de milho, destacando-se como vantagens o efeito residual longo conferido pela flubendiamida como ponto positivo para esta associação. O piretroide tem efeito rápido, pois sua absorção é imediata apos entrada no trato gastrointestinal, o que confere mortalidade rápida para a população de lagartas. Estes autores relataram também eficiência aumentada no uso da associação destes ingredientes comparando-se com seu efeito isolado. O efeito positivo da lambdacilotrina no controle da lagarta do cartucho foi verificado também por WANGEN et al (2015), que demonstraram elevada eficiência (mortalidade de lagartas $>95 \%$ aos 7 DAA), superando outros inseticidas como clorpirifós e cipemetrina.

O controle biológico tem se mostrado eficaz no controle de lagarta do cartucho em diversas regiões brasileiras (VALICENTE; TUELHER, 2010). A eficiência um pouco reduzida do controle biológico neste trabalho (resultados de matérica seca estatisticamente iguais aos da testemunha) pode estar associada ao fato de que a ação do vírus na mortalidade das lagartas é mais tardia em relação ao controle químico, permitindo que as lagartas causem danos nas folhas por mais tempo antes de morrerem. Níveis de mortalidade acima de $80 \%$ com controle químico foram atingidos após 4 dias após aplicação, enquanto para o controle biológico estes níveis só foram atingidos após 6 dias após a aplicação (CORRÊA et al., 2012).

Outras pesquisas também encontraram resultados semelhantes ao presente trabalho quanto à eficiência do baculovírus. Diniz et al. (2018) verificaram que o tratamento com baculovírus foi eficaz, e apresentou taxas elevadas de eficiência de controle ( $>85 \%)$, no entanto foi observado leve redução da área foliar nas plantas tratadas com baculovírus, comparadas ao controle químico, devido ao fato das lagartas demorarem um pouco mais para morrer após a aplicação do produto no controle biológico.

Bolonheiz et al. (2010) testaram a eficiência do baculovírus e do inseticida lufenuron (inibidor da sintese da quitina) na eficiência de controle da lagarta do cartucho em plantas de milho, testando diferentes níveis de infestação (alta, média e baixa). De forma semelhante a este trabalho, os autores relataram um nível de dano um pouco superior nas plantas tratadas com Baculovírus comparado as plantas tratadas com o inseticida. Os autores verificaram que, para a condição de alta infestação, o número de lagartas sobreviventes após 72 hs de aplicação dos produtos foi de 0,12 por planta para o controle químico, enquanto que para o baculovírus, foi de 1,62 lagartas por planta. A eficiência de controle dos dois produtos só foi semelhante após 7 dias da aplicação. Isto ocorre pois, como citado no parágrafo anterior, o Baculovírus demanda um tempo maior de ação, pois as formas oclusas do vírus precisam ser ingeridas, dissolvidas no intestino, para que a partir daí, infectem as células das lagartas e expressem os sintomas que levarão a mortalidade (BOLONHEIZ et al., 2010; BALZAN et al., 2019).

Nesse sentido, estudos estão sendo conduzidos para obter isolados de maior virulência (BEHLE; POPHAN, 2012), bem como pesquisas de manipulação genética (GRAMKOW et al., 2010), que reduzam o tempo da entrada do vírus no organismo da lagarta até a sua morte. Além disso, fatores como densidade populacional de lagartas e o ínstar predominante na população no momento da aplicação, podem aumentar ou reduzir a eficiência de controle pelo Baculovírus (BOLONHEIZ et al., 2010). A eficiência de ação do baculovírus é maior quanto menor for o ínstar, e consequentemente menor o tamanho, da lagarta (BALZAN et al., 2019). Lagartas maiores demoram ainda mais tempo para morrer do que as menores (HIRAN et al., 2010). Assim, recomenda-se que as pulverizações com baculovírus sejam feitas na fase inicial da cultura, aumentando as chances de atingir as lagartas nos primeiros ínstares, e elevando a eficiência do controle biológico (HIRAN et al., 2010; KAHLA et al. 2014).

Nesse sentido, no atual trabalho, os menores valores de notas da Escala Davis verificados no tratamento com baculovírus em dose dobrada aplicada uma única vez (13 DAP; T2), com relação ao tratamento aplicado em 2 vezes (13 DAP e 26 DAP; T3) provavelmente 
estão relacionados a essa maior eficiência de controle em aplicações iniciais. A aplicação inicial de dose dobrada pode ter sido mais efetiva por atingir as lagartas menores, levando a maior letalidade e controle.

O tempo até a mortalidade e a eficiência de infecção do vírus também podem ser afetados pelas condições climáticas. Temperaturas menores do que $20^{\circ} \mathrm{C}$ ou incidências muito elevadas de radiação UV podem diminuir a viabilidade e taxa de infecção do virus (KAHLA et al. 2014). Portanto, segundo Diniz et al. (2018), deve-se desenvolver formulações que apresentem efeitos protetores, e inibam efeitos climáticos, sobretudo da radiação solar, para aumentar a viabilidade do baculovírus.

Ressalta-se também que alguns trabalhos relatam aumento da eficiência no controle de lagartas quando o uso do baculovírus está associado ao uso de outras técnicas ao longo do ciclo da cultura, como uso de controle químico com inseticidas seletivos ou mesmo outras estratégias de controle biológico (WAGUIL et al., 2020). Verifica-se que é possível combinar este tratamento biológico com alguns inseticidas em subdose visando efeito sinérgico (BOLONHEIZ et al., 2010). O baculovírus é uma estratégia importante para o manejo integrado de pragas, e embora no geral, apresente um tempo um pouco mais longo para a mortalidade de lagartas comparativamente a alguns inseticidas químicos, seu uso deve-se ser ampliado pelos produtores. Da mesma forma, deve-se incentivar a busca de estratégias de manejo e tecnologias que aumentem a eficiência do vírus, como aplicações nos estágios iniciais da cultura, seleção de isolados mais eficientes e formulações protetoras.

\section{CONCLUSÃO}

Conclui-se que o uso do controle biológico é uma estratégia eficiente para o controle de Spodoptera frugiperda, e pode ser feito em aplicação única com dose dobrada no início do desenvolvimento da cultura, não necessitando realizar-se três aplicações parceladas do produto.

\section{REFERÊNCIAS}

BARBOSA, J.C.; MALDONADO JR., W. AgroEstat: sistema para análises estatísticas de ensaios agronômicos. Versão 1.0. Jaboticabal: Departamento de Ciências Exatas, 2010. BOLZAN, F. T.; FOLLMANN, D. N.; MENEGHETTI, C. B.; PICON, L. C.; RIBEIRO, A. L. P. Biological Pest Control in Maize Crop in Brazil: A Review. Journal of Agricultural Science, v. 11, n. 18, 2019.

BEHLEA, R. W.; POPHAM, H. J. R. Laboratory and field evaluations of the efficacy of a fast-killing baculovirus isolate from Spodoptera frugiperda. Journal of Invertebrate Pathology, v. 109, n. 2, p. 194-200, 2012.

BOLONHEIZ, H.; OLIVEIRA, N. C.; BALAN, M. G. Eficiência de Baculovirus spodoptera e lufenuron no controle de diferentes ínstares e densidades populacionais da lagartadocartucho em milho. Rev. Ciências Exatas, da Terra e Ciências Agrárias, v.5, n.1, p.8-13, 2010 .

COMPANHIA NACIONAL DE ABASTECIMENTO (CONAB). 2019. Boletim da Safra de Grãos. Disponível em: https://www.conab.gov.br/info-agro/safras/graos/boletim-da-safra-degraos> Acesso em: 05 mar 2020. 
CONTINI, E.; MOTA, M. M.; MARRA, R.; BORGHI, E.; MIRANDA, R. A. de; SILVA, A. F. da; SILVA, D. D. da; MACHADO, J. R. de A.; COTA, L. V.; COSTA, R. V. da; MENDES, S. M. Milho: Caracterização e Desafios Tecnológicos. Nota Técnica 2, Série Desafios do Agronegócio Brasileiro, 2019, 45 p.

CORREAA, M. B. ; OLIVEIRA, N. C.; VALICENTE, F. H. Manejo da lagarta-do-cartucho na cultura do milho: Aplicação de Baculovirus spodoptera isolado e associado com inseticida. Campo Digital: Revista de Ciências Exatas e da Terra e Ciências Agrárias, v.7, n.1, p. 59-67, 2012.

CRUZ, I.; VIANA, P. A.; WAGUIL, J.M. Milho: Pragas da Fase Vegetativa e Reprodutiva. In: AGEITEC: Agência Embrapa de Informação Tecnológica. Disponível em: https://www.agencia.cnptia.embrapa.br/gestor/milho/arvore/CONTAG01 69 16820051120.h tml. Acesso em: 04 mar 2020.

DAVIS, F. M.; NG, S.; WILLIAMS, W. P. Visual rating scales for screening whore-stage com resistance to fall armyworm. Mississipi: Mississipi State University, p.9, 1992, Technical Bulletin, 186.

DINIZ, N. F.; LUSKI, P. G. G.; QUEIROZ, A. P.; SILVA, N. R. A.; BUENO, A. de F.; NEVES, P. M. O. J.; OLIVEIRA, M. C. N. Baculovirus spodoptera associado com herbicidas no controle de Spodoptera frugiperda. 2018. XIII Jornada Acadêmica da Embrapa Soja. Disponível em: < https://ainfo.cnptia.embrapa.br/digital/bitstream/item/183240/1/p-27-37Doc401-XIII-JA.pdf> Acesso em: 20 abr 2020.

FANCELLI, A. L. Visão sistêmica e estratégias de manejo são imperiosos para garantir cultura sustentável. In: FANCELLI, A. L. et al. (Ed.) A cadeia produtiva do milho. Revista Visão Agrícola, n. 13, p.58-60, 2015.

FUNDATION OF AGRICULTURE ORGANIZATION (FAO). Agriculture Production Dataset. Disponível em: http://www.fao.org/faostat/en/\#data/QC> Acesso em: 04 mar 2020.

GRAMKOW, A.W., PERECMANIS, S., SOUSA, R.L.B. Insecticidal activity of two proteases against Spodoptera frugiperda larvae infected with recombinant baculoviruses. Virology Journal, n.7, v.143, 2010.

HIRAN, B.; OLIVEIRA, N. C.; BALAN, M. G. Eficiência de Baculovirus spodoptera e lufenuron no controle de diferentes ínstares e densidades populacionais da lagarta-docartucho em milho. Campo Digital, v.5, n.1, p.8-13, dez., 2010.

KALHA, C. S.; SINGH P. P.; KANG, S.S.; HUNJAN, M. S.; GUPTA, V.; SHARMA, R. 2014. Entomopathogenic Viruses and Bacteria for Insect-Pest Control. In: Abrol, D. (ed) Integrated Pest Management Current Concepts and Ecological Perspective, Academic Press, p. 225-244.

MIRANDA, R. A. de. Uma história de sucesso da civilização. A Granja, v. 74, n. 829, p.2427, jan. 2018. 
OLIVEIRA, C.M.; AUAD, A.M.; MENDES, S.M.; FRIZZAS, M.R. Crop losses and the economic impact of insect pests on Brazilian agriculture. Crop Protection, v.56, p.50-54, 2014.

OLIVEIRA, H. F.; NUNES, J. Eficiência de inseticidas no controle de Spodoptera frugiperda na cultura da soja. Cultivando o Saber, FAG: Edição Especial 2017, p. 162-176. Disponível em: $<$ https://www.fag.edu.br/upload/revista/cultivando_o_saber/5a3812bf28ade.pdf $>$ Acesso em: 10 abr 2020.

TOSCANO, L.C.; CALADO-FILHO, G.C.; CARDOSO, A.M.; MARUYAMA, W.I.; TOMQUELSKI, G.V. 2012. Impacto de inseticidas sobre Spodoptera frugiperda (Lepidoptera, noctuidae) e seus inimigos naturais em milho safrinha cultivado em Cassilândia e Chapadão do Sul, MS. Arquivos do Instituto Biológico, São Paulo, v.79, n.2, p.223-231

\section{UNITED STATES DEPARTMENT OF AGRICULTURE (USDA). Dados e Análises}

Culturas Agrícolas. Disponível em: http://www.usdabrazil.org.br/pt-br/dados-e-analises/> Acesso em: 03 mar 2020.

VALICENTE, F.; TUELHER, E. S. Controle biológico da lagarta do cartucho, Spodoptera frugiperda, com baculovírus. Circular técnica Embrapa, n. 4, Sete Lagoas, 2010, 14 p. WAGUIL, J.M.; VIANA, P. A.; CRUZ, I. Manejo Integrado de Pragas. In: AGEITEC: Agência Embrapa de Informação Tecnológica. Disponível em: https://www.agencia.cnptia.embrapa.br/gestor/milho/arvore/CONTAG01_69 16820051120.h tml. Acesso em: 04 mar 2020.

WANGEN, D. R.; PEREIRA JÚNIOR, P. H. S.; Santana, W. S. Controle de Spodoptera frugiperda (J. E. Smith, 1797) na cultura do milho com inseticidas de diferentes grupos químicos. Enciclopédia Biosfera, Centro Científico Conhecer, v.11 n.22; p. 2015.

Publicado em 27/08/2020 